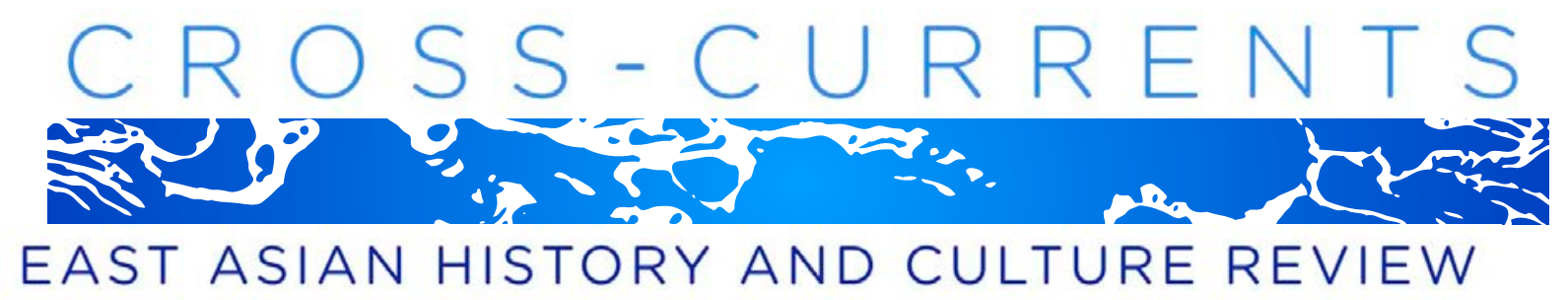

\title{
The Game People Played: Mahjong in Modern Chinese Society and Culture
}

Maggie Greene, Montana State University

\begin{abstract}
This article considers the discourse surrounding the popular Chinese table game of mahjong in the nineteenth and twentieth centuries, using it as a barometer to trace social and cultural changes during the late Qing and Republican periods. After analyzing the connection between mahjong; its forerunner, madiao; and their antithesis, weiqi (go), it traces the changing position of mahjong in Chinese society from a game seemingly loathed by literati to a staple of bourgeois parlors. Drawing on a variety of journals, newspapers, and visual sources, the article further explores culture from class and gender perspectives in the late Qing and Republican periods, as mahjong moved from a visibly male activity to one largely associated with women. Finally, it considers the relationship between games and discourses of modernity, and the important changes taking place regarding leisure time in the twentieth century. The article argues that mahjong has been uniquely resistant to regulation and control. Enjoyment of the game spread across class and gender lines, despite the efforts of reformers, for reasons that reflect and embody key shifts from the late Qing dynasty through the end of the Republican period.
\end{abstract}

Keywords: China, Republican, Qing, mahjong, madiao, weiqi, go, games, leisure

In 1927, the eminent Chinese writer Hu Shi lamented the contrast between China's national pastime and those of other countries. England had cricket; America had baseball; Japan had wrestling. "And China? China's national game," he wrote, "is mahjong” ([1927] 1998, 45). Hu Shi then suggested that the game was dangerous enough to the fledgling Republic of China that it should be classed along with footbinding and opium as a great social peril. If each game of mahjong required four hours, he famously calculated, the million games of mahjong played each day in China wasted four million hours a day! Yet "no one" thought of mahjong as injurious to the nation ([1927] 1998, 48). In fact, despite his critique, Hu Shi himself spent many an evening 
playing the game with friends. Perhaps it was this intimate awareness of how pleasurable a diversion mahjong could be that informed his criticism.

Hu Shi's early twentieth-century anxieties over mahjong were, in many respects, nothing new. From the game's emergence in the 1800s, Chinese moralists and reformers wrung their hands as they complained bitterly of its popularity - while perhaps indulging in a few hands themselves. In so doing, they harked back to an older strain of criticism: certain scholar-officials had identified madiao, mahjong's ludic predecessor, as one contributor to the Ming dynasty's collapse. These games seemed to be harbingers of dynastic downfall and destruction, their broad popularity signaling society's crumbling moral foundations. However, unlike footbinding and opium, mahjong was not the focus of sustained campaigns of eradication. While tile games were sporadically banned, few government entities tried to enforce control over mahjong in the home. And yet mahjong was a ubiquitous topic, lurking quietly on the pages of radical Qing newspapers and flickering across Republican movie screens. A silent symbol of declining morality and wasted hours, mahjong moved from being a cause of China's problems to being a signal of a society in the throes of moral decay.

Mahjong was played by the wealthy and the poor, men and women, urbanites and villagers; in short, it was a game that enjoyed nearly unrivaled popularity. A focused scholarly examination of mahjong provides an opportunity to elucidate relationships of leisure and the state, nationalism, and modernity, and sheds light on the social turbulence of late nineteenth- and early twentieth-century China. Unlike other targets of reformers, such as opium use and prostitution, mahjong may have encouraged morally harmful behavior, but it left no markers of illness on physical bodies. Often played at home, in parlors and back rooms, the game was not a public problem. Not was it popular only in China; it also spawned crazes in Japan and the West. Mahjong was a "patented product" of China that attracted — and continues to attract-foreign fans.

Games (particularly those with broad popularity) are unique media with which to undertake historical inquiry. On the one hand, they are often described as trifling amusements; on the other, their sheer popularity and broad distribution in society allow insight into varied parts of society. Furthermore, as generally private activities, mahjong and other similar pleasures were largely free from state intervention. Anti-gambling campaigns notwithstanding, mahjong occupied a conflicted position in Chinese society, and it is this status that makes it a valuable 
object of historical inquiry. In this article I will not address changes to game play, but instead show the utility of considering the social, cultural, and political position of games and other leisure activities.

This article tracks changing criticisms of mahjong from the late Qing dynasty (16441911) through the end of the Republican period (1911-1949), particularly concerning the game as an urban phenomenon. In tracing criticisms of mahjong from the moralizing concerns of dour Qing scholar-officials to nationalistic critiques leveled after 1911, I illustrate that mahjong is a useful subject for historical inquiry because the game cuts across lines of class, gender, and locality. In exploring why mahjong proved to be such an enduring problem for Chinese intellectuals and politicians, I analyze mahjong; its forerunner, madiao; and their antithesis, weiqi, through distinctions of class and gender. I examine the constructed relationships of morality, time, and nationalism, and the attempts of reformers to imbue every aspect of daily life with some redeeming progressive characteristics. These included adding notions of "national health" and "wasted time" to the discourse on games and leisure during the Republican period, as efforts to build a strong, modern nation took hold. I also investigate the shifting associations of mahjong, which went from a staple of brothels and teahouses to a game enjoyed by bourgeois families in their modern homes. I argue that this move from pleasure quarters to eminently respectable bourgeois households provides one reason for mahjong's enduring popularity, as well as for its resistance to regulation and control. The discourse about mahjong reflects many key shifts from the late Qing to the Republican era.

\section{Origins}

Mahjong (majiang) is a game for four players, played with a set of 144 tiles grouped into two major sets: the "number" tiles and the "honor" tiles (figure 1). Number tiles are divided into three suits, each representing different denominations of traditional coins. Each suit includes tiles numbered one through nine. The honor tiles are not numbered and are divided into four directional "winds" and three "dragons." Both the honor and number tiles include four of each tile, for a total of 136 tiles. Finally, sets include eight unique, optional tiles called "flower tiles," often fancifully decorated (Lo 2001, 3-4). The goal in all variations of the game is to create winning hands by discarding and drawing new tiles (Lo 2001, 10). As in numerous Western 
trick-taking card games, there are many combinations that can make up a winning hand, with rarer types worth more points (Gibson [1974] 2013, 7-8).

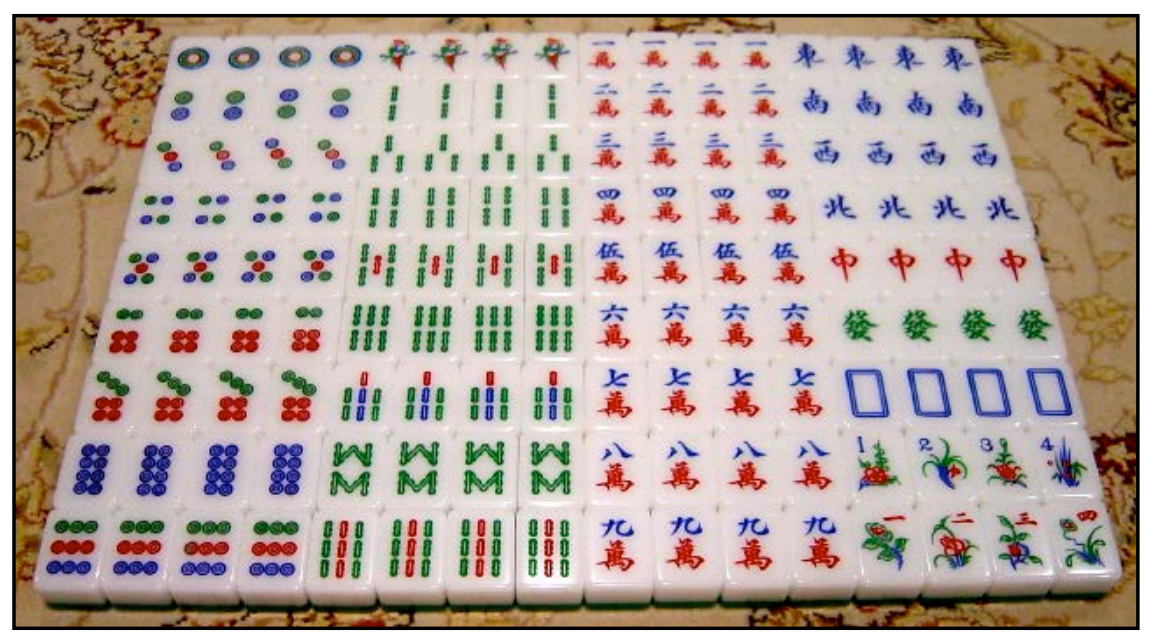

Figure 1. A modern set of 144 mahjong tiles, with "number" tiles in the first twelve columns from the left and "honor" tiles in the four right-hand columns. Source: Wikimedia Commons.

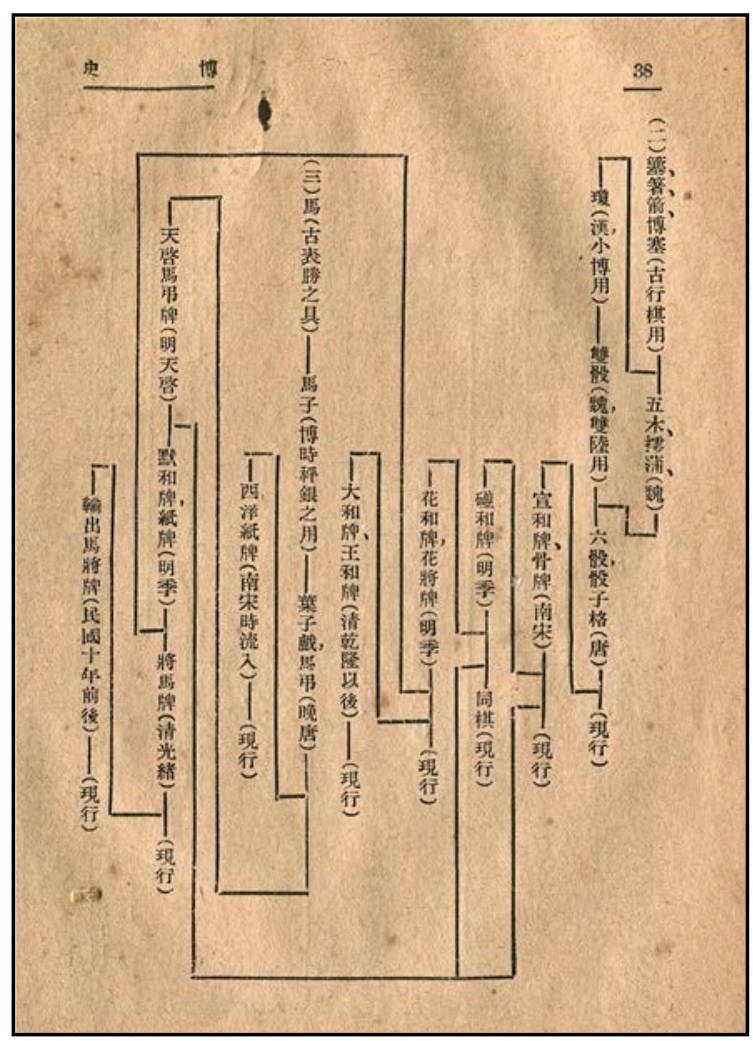

Figure 2. Du Yaquan's genealogy of mahjong, beginning with various pai games on the right and ending with what he considers modern mahjong, dated to the 1920s. Source: Du Yaquan, Boshi (38). 
Mahjong's precise origins have been lost to time, but its tile set almost certainly derives from the older tile game of madiao. Writer and editor Du Yaquan's influential 1933 history of gambling suggests that mahjong grew out of the mixture of madiao with various other tile games (pai) throughout the Qing dynasty (figure 2). Du identifies these two strains coalescing into what he terms jiangma pai by the nineteenth century. He locates the origins of majiang pai-modern mahjong - in the first decade of the Republican period. Du places mahjong's rise in popularity in southern China following the First Opium War (1839-1842) and the opening of treaty ports. In a fluid environment where "buyers from every province" gathered alongside drifters without permanent residences, the game of mahjong spread like wildfire (Du 1933, 33-34).

The author Xu Ke's Classified Collection of Qing Notes also traces mahjong to midnineteenth-century southern China, during the Taiping Rebellion (Xu [1917] 1984-1986 ). Mahjong soon spread all over China, even finding passionate devotees in the Qing court (Xu [1917] 1984-1986, 4906). While Xu's anecdote of Manchu royalty and noblewomen enjoying a mahjong game is possibly fictive, exquisitely decorated mahjong sets indicate that the game was enjoyed by the elite. And although few sources offer concrete details of how and when mahjong developed, there is a clear association with the traumatic years of the Opium Wars and the Taiping Rebellion.

Mahjong, like its predecessors, enjoyed widespread popularity in Chinese society. However, these games had already attracted the ire of scholar-officials by the end of the Ming dynasty (1368-1644). The scholar-official Wu Weiye (1609-1671) wrote that "the Ming dynasty was lost-lost on account of madiao" (Hu 1998, 47). The officials of the Ming were-in Wu's opinion-wasting time (typified by excessive enjoyment of the tile game) as their world crumbled; we might draw parallels to the Western maxim of "Nero fiddling as Rome burned." The association of madiao and mahjong with decadent, frivolous pleasures-symptoms of moral decay in a time of crisis, and a symbol of corrupt officials - would continue through the twentieth century. But it is worth noting that the other famous table games of China, weiqi (better known by its Japanese name, go) and xiangqi (similar to chess), receive no such vitriolic assessment from elites. On the contrary, many viewed mastery of weiqi in particular as an important and beneficial skill to cultivate.

Weiqi is a game for two players, played on a $19 \times 19$ grid. Using stones, players attempt to encircle their opponents' pieces, thereby removing them from the playing field (Lo and Wang 
2004, 187). Unlike madiao or mahjong, weiqi has legitimately ancient origins. Du Yaquan dates it back to as early as the Warring States period (475-221 B.C.E). Although the archeological and philological record does not support so ancient a beginning, the veneer of Confucian legitimacy went a long way toward making weiqi a respectable game (Lien 2006, 567-568, 571). Not only was weiqi well pedigreed, but by the Tang dynasty (618-907 C.E) it was regarded as one of the "four arts"-along with calligraphy, painting, and playing the zither-that cultivated men were expected to study (Z. Chen 2001, 200-201). Weiqi was even a popular subject for poetry. One official mused on the lovely acoustic qualities of his bamboo tower: "It is a good place to play the [zither], for the musical melodies are harmonious...; it is a good place to chant poems, for the poetic tones ring pure...; it is a good place to play [weiqi], for the stones sound out click-click" (Z. Chen 1997, 644).

Mahjong tiles, too, make a satisfying noise, but literati studiously refrained from waxing rhapsodic on the pleasures of the game. Perhaps the suspect origins of madiao, and later mahjong, were the root of the problem. While weiqi could be "found" (however spuriously) in Confucian texts, madiao and mahjong enjoyed no such record of ancient origins and were often associated with traumatic periods of upheaval and decline. Perhaps just as important was how the games were played. Weiqi, despite being a game for two players, is frequently represented as an individualistic activity. In the poem above, weiqi is grouped with other quiet activities. While these may all be enjoyed with others, they are also solitary pleasures. It is the development of individual skill and talent, through careful self-cultivation, not the dynamics of group play, that is frequently emphasized in weiqi literature.

Equally important as this emphasis on self-cultivation were perceptions of game mechanics. Mahjong would be critiqued in the twentieth century for being too combative and not encouraging teamwork. Why, then, was weiqi, an "intrinsically... antagonistic or warlike game," not subject to the same criticisms? The literary scholar Chen Zuyan argues that because weiqi was a game "governed primarily by skills developed in handling strategic operations and tactical encounters," it satisfied the desire of men of letters to also be men of war $(1997,645)$. Weiqi's "approximation" of military strategies supposedly gave it some weight as a training ground for thinking in abstract patterns and developing an understanding of specific strategies (Z. Chen, 1997, 645-646). Surely, mahjong — a game that requires no small measure of strategy—could 
offer the same sort of utility? In the minds of many Chinese intellectuals, however, the answer was "absolutely not."

The game studies scholar Dan Dixon has offered a reading of "Dionysian playing" and "Apollonian gaming" that can be applied to mahjong, madiao, and weiqi, and suggests one way of thinking about the different attitudes toward the games. Apollonian gaming-here, weiqi-is marked by the individualistic pleasures of problem solving, understanding a system, and so forth. Dionysian playing - typified by madiao and mahjong - emphasizes a shared, social experience $(2009,6,10)$. Tile games were inherently social; game play was often less important than the comradeship found around the playing table, standing in stark contrast to the perception of weiqi as a relatively solitary activity, marked by self-cultivation and long reflection. Furthermore, the fondness of China's literati for mapping world order to games, or at least to weiqi, explains one reason mahjong found so little favor. The parallels between cosmic order and a weiqi boardsummed up by a line of poetry reading, "The cosmos is [a weiqi] board"-where order emerges out of seeming chaos while playing the game - goes a long way in explaining the attraction to and positive impression of weiqi (Z. Chen 1997, 650). This ability to render the opaque lucid is a key element of "the Apollonian." While it is safe to say that even the most worldly of late Qing and Republican Chinese intellectuals were not pondering games in Nietzschian terms, the interdependent relationship of the Apollonian and Dionysian helps explain why weiqi could be praised for the same characteristics that mahjong was vilified for.

As the philosopher Robert John Ackermann has argued, "the Apollonian is a mode of representation... that allows human beings to have a grasp of the Dionysian in a bearable or intelligent form" (1990, 55). Apollonian games (such as weiqi) allow players to control, by means of cultivation, the game environment; Dionysian games (such as mahjong and madiao) do not. Furthermore, mahjong is always included as part of gambling (dubo) games; weiqi is not. Dubo refers to games associated with money, to be sure, but is more problematically associated with chance (Papineau 2000, 223-225). In the context of official life, such games (like madiao and mahjong) underscore the capricious nature of fate: hard work and cultivation are not enough to ensure success. It is possible that one's competitors will have been dealt a better hand, and all the talent in the world will not be able to make up for a starting deficit. Weiqi, on the other hand, starts both players with a clean slate, and success comes through diligent practice. If the "cosmos 
is a weiqi board," then players who have a mastery over strategy — one that has been acquired through hard work, not passively received — will emerge victorious.

The ways in which mahjong and weiqi have historically been discussed underscore these perceptions. Mahjong requires skill, but it also requires "cleverness" and "quick thinking," and is unsuited to quiet contemplation. The anthropologist Paul Festa notes that "almost without exception," his mahjong-playing informants in contemporary Taiwan describe the outcomes as "twenty-percent skill and eighty-percent luck" $(2007,109)$. Weiqi, on the other hand, is seen as confirmation that careful cultivation will triumph in the end - a sign that the cosmos is fair, rational, and meritocratic.

The literati's express distaste for madiao and mahjong belies their positions as games inextricably tied to scholar-official life, for better or worse. Even disapproving literati had a difficult time denying that the games enjoyed a wide popularity among political and cultural elites. One seventeenth-century scholar noted that it seemed hardly a single person was not playing the game in important political and cultural centers, positing that it was perhaps boredom that led the craze (X. Chen 2009, 145). There was another aspect, however, to madiao and mahjong's social status. Xu Ke lists a "mediocre skill" (that is, the ability to lose to superiors) in weiqi and madiao as one of the keys to official success in provincial capitals ([1917] 1984-1986, 1595). It is not unreasonable to assume that mahjong had begun to supersede madiao as the other game of official life by the late Qing dynasty (X. Chen 2009, 150).

This ability to play, but lose gracefully to superiors, recalls an incident among women in the Qing writer Cao Xueqin's novel Story of the Stone (Honglou meng), in which the younger women conspire to lose to Grandmother Jia, delighting the older woman in the process (Cao 1977, 430-432). While the specific game is not named (it is simply noted as a generic pai), it is not difficult to imagine the game as madiao or one of mahjong's huapai forerunners. Though the presence of the unnamed pai in a gentry household in decline would probably confirm the opinions of $\mathrm{Wu}$ Weiye and others that the ardent playing of flippant games such as madiao was a potent symbol of disaster - either national or familial-looming on the horizon, it may also be read as showing appropriate respect for one's elders or superiors, which may or may not lead to material gains (promotion, money, elevation of status). In a less materialistic sense, the "gain" could be the replication of proper social relations, even in a competitive setting. The anecdotes also illustrate the social nature of mahjong and madiao: the group dynamic of the game is 
highlighted in Story of the Stone. The inclusion of mahjong ability (particularly the ability to lose gracefully) in the list of Xu Ke's "ten attributes" for official success further reinforces the essential social aspect of the game.

The Dutch historian Johan Huizinga read these types of situations as "competition for honour," or a "contest in politeness," whereby one could "[demolish] one's adversary by superior manners, making way for him or giving him precedence" $(1971,66)$. The fact that this game-within-a-game apparently applied to weiqi as well as mahjong undercuts one of the primary differences between the games (at least in how critics conceptualized them). Is the winner of a weiqi match truly the most skilled, or did his position win the game for him? This topic is not one madiao and mahjong critics brought up: the emphasis on personal experience and cultivation to the exclusion of the social element of weiqi allowed fans to neatly sidestep some of the potential unpleasantness of relations in the human world.

Combining the gambling issue with concerns over bad officials and greedy social climbing may suggest yet another reason mahjong was so detested. While the ability to lose gracefully at weiqi is, indeed, noted as a useful skill-this is one of the few times madiao and weiqi stand side-by-side as near equals (notably, in a critique of bureaucratic culture in general) - the literary and cultural precedents for weiqi's position as a sublime pastime is one that madiao and mahjong do not share. Madiao, from the waning years of the Ming dynasty onward, assumes a negative connotation: the game that lost the dynasty. Mahjong was linked back to this discourse as the Qing dynasty crumbled and acquired even more negative overtones due to the period of its emergence. Mahjong is tied to traumatic events that signaled the decline of the Qing: humiliating defeats in the Opium Wars, the opening of treaty ports, and widespread destruction caused by the Taiping Rebellion. Weiqi rested comfortably on its Confucian heritage, but mahjong had no such illustrious history and, in fact, had a host of associations most people would be happy to forget.

\section{Mahjong and Urban Society}

From its origins in the crowded southern Chinese cities of the mid-nineteenth century onward, mahjong appears to have been primarily an urban phenomenon, albeit one enjoyed by players drawn from all classes of society. For reformers and moralists, it was mahjong's position in treaty ports and bourgeois parlors, and not the countryside, that was most concerning. When 
the writer Lu Xun described a fictional country bumpkin's return to his small village from a larger town, he emphasized the exotic nature of mahjong. Villagers "couldn't manage anything better than a game played with thirty-two bamboo counters. Here only the Fake Foreign Devil knew how to play Ma John, but in town every little shitkicker on the block knew it up one side and down the other" (Lu 1990, 142). ${ }^{1}$

In August 1909, the newspaper Shenbao reported that the Ministry of Civil Affairs was implementing a ban on gambling in Beijing. While mahjong is not specified by name, the ban proscribed card gambling (paidu), a category that would include mahjong and other tile games ("Minzhengbu" 1909). Of more interest is where implementation of the ban would begin: the brothels of Bada Hutong, a notable Beijing red-light district. When the scholar Liang Shiqiu asked his father about mahjong, his father responded sharply, "Thinking about playing mahjong? Go to the Bada Hutong!" This response so frightened young Liang that he did not dare mention the game again, and he retained a "bad impression" of it until he became friendly with $\mathrm{Hu}$ Shi and other expert players (Li 2009, 27). Mahjong's status as a gambling game, and its association with seedier elements of society, would carry over into the Republican period. Mahjong was associated with excess and decadence: prostitution, drinking, and opium smoking. Yet it also maintained a conflicted status, particularly as it began to saturate the domestic realm of bourgeois housewives. Thus, for some critics, mahjong was at once a symptom of China's backwardness and moral decay and a symbol of detestable upper-class decadence.

Han Banqing's sprawling 1892 novel Flowers of Shanghai (Haishang hua) centers on wealthy patrons of Shanghainese brothels and the beautiful "flower girls" that serve them. Drinking, opium smoking, and mahjong games make frequent appearances, alongside romances, attempted murder, and numerous other dramatic turns. The image of total excess is clear: "Sometimes, guests play [mahjong]," complains one girl, "and I have to stay up all night. By the time the game is over at dawn, they all go to bed." (Han 2005, 184). Even servants and maids pass the time between clients by playing a few hands. However, women are frequently absent from the actual playing of mahjong in the novel. In one scene, only one girl remains "on call" during a mahjong game between male clients. She sits behind her client, mere decoration for the game, which eventually begins after consumption of alcohol and opium and a significant outlay of cash (Han 2005, 209-210). 
Mahjong was indeed an important activity in brothels. As primary sources of income for courtesan houses, gambling parties and banquets encouraged a sensual atmosphere in which men could enjoy the company of women and interact with other men in a "congenial environment" (Hershatter 1997, 94-95). Unlike weiqi, mahjong was usually situated in an intensely social context. Money and alcohol appear to have flowed quite freely, and madams preferred clients who liked gambling and drinking (Hershatter 1997, 95). By 1939, one round of mahjong could cost between 24 and 48 yuan (by comparison, a ticket to a Hollywood film at a plush movie theater cost between 1 and 3 yuan). One decadent evening of drinking, eating, and mahjong could cost patrons several hundred yuan (Hershatter 1997, 135). Tile games, once associated with frivolous literati, could now be linked to sensual excess. Mahjong terminology even found its way into descriptions of conflicts between customers over a courtesan (Hershatter 1997, 135$136)^{2}$

But mahjong was also enjoyed beyond the elite pleasure quarters. The earliest extant Chinese film, Laborer's Love (1922, dir. Zhang Shichuan) offers a contemporaneous glimpse into the underbelly of Republican Shanghai. The main character is an earnest fruit peddler trying to find love on the mean alleys of Shanghai. His foils are the boisterous small-time crooks who hang out in the little teahouse next door to his fruit stand, and the patrons and courtesans of the "all-night club" above his apartment. One night, the peddler is kept awake in his modest apartment by the activities upstairs. After showing a clock indicating it is close to 10 P.M., the action moves upstairs to the club, where a mahjong party is going on. The implication is that the clatter of tiles and party noise are keeping the hero awake. While four men are seated at the mahjong table, the women merely look on and do not participate. The action grows more and more animated as the first round comes to a close. Finally, one man jumps up in excitement, declaring, "Double sevens!"; the camera lingers on the table and the winner's hand. The players soon sit down for another round - until a fight breaks out among the spectators. Mahjong is represented as part of the decadent world of urban clubs, set in stark contrast to the hard-working fruit peddler and other residents trying to eke out a meager living.

The association between mahjong and baser social elements was not confined to Chinese observers alone. In 1925, the Japanese professor Aoki Masaru commissioned a series of paintings-later published as Pekin fuzoku zufu [Illustrations of Beijing customs]-depicting many aspects of life in Beijing. One series of three images illustrates some pleasurable (and 
morally suspect) pastimes: sandwiched between two well-dressed gentlemen inspecting beauties spilling out from behind a curtain in a "tea house" and opium smokers lounging while puffing on their pipes is a lively game of mahjong (Aoki 1964, unnumbered plate). It doesn't seem accidental that mahjong is slotted alongside a teahouse of ill repute and opium. And yet, by the twentieth century, mahjong not only was attracting players from the upper echelons of Chinese society, but had fans in Japan and the West, as well. Despite being a trifling matter, mahjong was a concern for reformers because it cut across class, gender, and geographical boundaries.

Mahjong's devotees were not simply patrons of urban brothels. Harking back to the seventeenth-century critiques of madiao, Chinese warlords like Zhang Zuolin were said to be passionate about the game. Zhang "appears at crucial times in his career... to have withdrawn into seclusion, where with his closest cronies he devoted himself to [mahjong], opium, and singing girls" (McCormack 1977, 253), an odd echo of earlier imperial criticisms of those officials who gave themselves over to diversions in the face of crisis. Mahjong was a constant feature of Zhang's life, even when he was "working," as he and members of his administration enjoyed the game nightly (McCormack 1977, 308).

Had mahjong been confined to teahouses, brothels, and nightclubs, and its players restricted to courtesans' clients, debauched warlords, and seedy urban elements, perhaps reformers and modernizers would not have troubled themselves with such strident denunciations of the game. The fate of traditional teahouse culture in Republican China offers one blueprint of what might have been. New cultural elites were disdainful of the backward, "decadent" teahouse and "everything it stood for" (Shao 1998, 1010). By "denigrating teahouses and their patrons of the uncouth 'other"' (Shao 1998, 1010), critics relegated teahouses to the lower strata of society, thus largely erasing them from the modern social landscape. This mirrors the furor over mahjong in many ways, not least in the insistence that teahouses - like the tile game-were considered "a negative influence on the new, Republican age" (Shao 1998, 1021). But unlike teahouses, mahjong was not sliding down the social ladder. On the contrary, its popularity seemed only to grow-even among new cultural elites like Hu Shi. The problem with mahjong was that it was equally at home in teahouses and brothels as in the new, modern parlors of the bourgeoisie. Mahjong was so dangerous because everyone, as reformers stressed, seemed enamored of the game. 
In comparison to other forms of gambling, like dice or cock fighting, mahjong could be played in the comfort of one's home, making regulation difficult. Furthermore, the very nature of the game seemed to attract players, such as bourgeois housewives, who would never dream of betting on a dice game. A 1940 article from a highbrow women's magazine laid out the differences between mahjong and other kinds of gambling. The author divides gambling games into two categories: fast games, in which money comes and goes quickly, and slow games (like mahjong) in which money ebbs and flows more gradually (Mei 1940, 17). The cautious person wouldn't dare start a fast game; the dangers of such kinds of gambling seemed obvious. But mahjong's more sedate pace and smaller transactions - stories of fantastically expensive brothel gatherings notwithstanding, most people played for token sums - meant that even cautious people were happy to play. "Old-style elderly men and women, middle-aged men from every profession, [and] a good number of housewives" all numbered among fans of the game- even "totally new modern youth" enjoyed it (Mei 1940, 17). Mahjong was a hidden danger, because many people didn't recognize it as a problem. And it had a place in the homes of perfectly modern men and women.

In a 1904 article in Zheijiang's radical Alarm Bell Daily News, one anonymous late Qing reformer suggested that, owing to mahjong's broad popularity, it could be used to edify the population, not simply to ensnare them in vapid evenings of gambling and socializing. ${ }^{3}$ The article, tucked between dispatches on the Russo-Japanese War (1904-1905) and important national matters, provides a more rational assessment of the game and its place in Chinese society, as well as its potential power, than can be found in most other critiques. "In observing the rise and fall of nations, one should not observe matters of great importance," the author wrote, "but instead look at trifling things" ("Majiang pai" 1904). Noting the difficulties of eradicating old customs entirely and tackling large issues, the author suggested that mahjong could make an excellent tool for education, with some modifications. As a broadly popular game, mahjong could be the perfect vehicle for reform on a small scale. The proposed new game needed to hit a sweet spot between alienating erudition and boring simplicity. Based on its sophisticated theme and complicated rule set, it was likely aimed at the relatively educated, urban consumer.

The earnest educational game dreamed up by the anonymous author of the article bore little resemblance to any variation of mahjong (figure 3). The dragon tiles were replaced with 
government types (autocracy, constitutional monarchy, and republic), while the directional tiles were mapped to four classes of people (farmer, worker, merchant, and soldier). The three traditional suits were assigned to continents (Asia, Europe, and the Americas); the nine tiles of each suit were assigned a country and corresponding government type (e.g., "Chinaautocracy," "England - constitutional monarchy"). A variety of other tiles were included: the five inhabited continents, the five major oceans, and modern forms of technology (steamship, railroad, printing, telegraph, and hot air balloon).

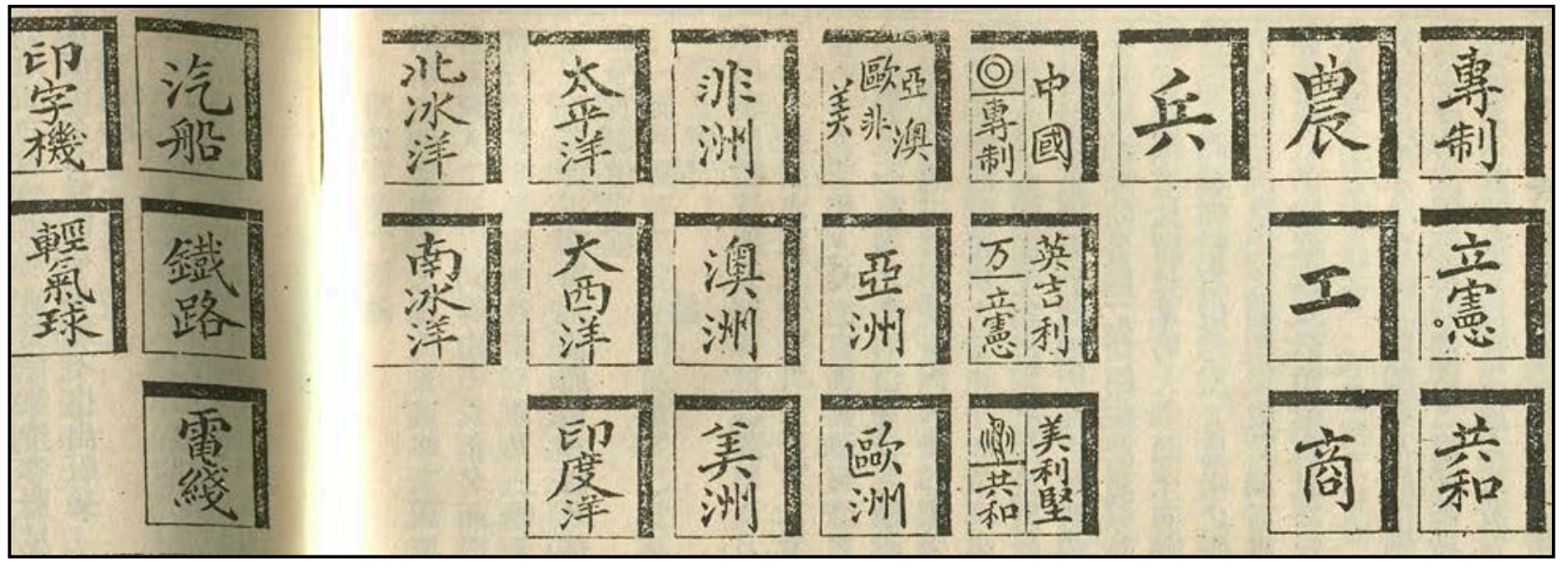

Figure 3. Tiles from the proposed version of reformed mahjong in the Alarm Bell Daily News. From the right, tiles include government types, classes of citizens, countries, continents, oceans, and technology. Source: "Majiang pai" (1904).

The rules were also complex. But the essence of play was that republicanism and technology ruled the table. Players facing a hand of autocratic nations or, worse yet, colonized Australian or African tiles had a nearly impossible task before them, being placed at a disadvantage in terms of the ability to draw new tiles. Dominance in this reformed mahjongand, by extension, the world of the late Qing - required the right government and the right technology. The player stuck with Africa or Australia had no hope of competing with the enlightened continent of Europe, and possessing technology alone would not save an autocratic China. While the rules make some logical sense, it is difficult to imagine anyone willingly settling down for a game of "imperialism in action." Unsurprisingly, reformed mahjong apparently made it no further than the pages of the paper. 
The anonymous proposal was relatively singular in a period that saw mostly complaints about the game, not ideas to make it more educational. In many ways, the general late Qing discourse surrounding mahjong is merely a continuation of earlier anti-madiao grumblings. Yet the emphasis that everyone — not just elite gentry and corrupt officials — was playing mahjong indicates a change in the discourse. Of particular importance was the position of respectable women (as opposed to courtesans). Intimately tied to the health of the nation, both in rhetoric and for their position as mothers, wives, and keepers of the household, social reformers laid special emphasis on women's enjoyment of mahjong. Brothels could be shut down and "fast" gambling games could be regulated into extinction, but mahjong in the Republican period would not be so easily rooted out of social clubs and urban, middle-class parlors.

\section{Mahjong and Women}

Women appear to burst onto the gambling scene in the Republican period. While they were certainly playing mahjong and its forerunners at home during the late imperial period, they received little or no attention from the moralists who turned a disapproving eye toward frivolous games. And while courtesans and madams made money from hosting gambling parties for wealthy male clients, the role of women seems to have been largely confined to sitting beside or behind players.

After the establishment of the Republic, anxiety over women playing mahjong and anxieties about modernity collided in places where respectable modern women gathered. The implications for "new China" of wives and mothers playing mahjong instead of focusing on maternal duties were terrible to contemplate, at least according to reformers. Urban women playing mahjong thus became symbols for all that was wrong with a modernizing China. If the delicate, footbound sing-song girl of Flowers of Shanghai could be written off as an old, decrepit China fading from view, the educated housewife with her high heels and fashionable clothes was a different problem altogether. Not unlike Wu Weiye's critique of madiao as a game that lost the Ming dynasty, controlling mahjong became a matter of national health and survival.

In 1935, the moralizing film Little Angel (dir. Wu Yonggang) presented a different picture of mahjong than the one seen in Laborer's Love. While the mahjong game in Love is no doubt bad for the health of the nation - prostitution and lavish banquets hardly being hallmarks

of modernity - the game gets a new setting and acquires more explicitly negative overtones in 
Angel. Revolving around the titular "little angel," the film follows the exploits of a young paragon of selfless do-gooding. Although his family is poor, in part because his father is doing his patriotic duty by serving in the army far from home, their affectionate interactions paint an idyllic picture of a household uncorrupted by polluting foreign or bourgeois influences. This poor-but-morally-intact family is contrasted with their next-door neighbors, who seem to have it made, with their large house, stylish modern parlor, and fashionable clothes. But all is not as it seems. Our first indication that this family has fallen into the trap of modern moral decay is the mahjong table lurking in the corner of the living room. As the historian Paul Pickowicz has described it, "The children are neglected, the women sit around playing [mahjong] all day, and the adulterous husband is... lusting after young women in the local night clubs, where he smokes, drinks, and dances to Western music" $(1991,62)$. At last, having stayed up all night with a sick child while her husband was out boozing, the bourgeois mother, in a fit of frustration and shame, flings her mahjong tiles out the window.

Although some features of the film run counter to what many forward-thinking reformers were advocating, the connection of moral decay, national health, and mahjong would be at home in any number of contemporaneous liberal journals. Mahjong became convenient shorthand for the many negative qualities of the bourgeois home. In less than fifteen years, the representation of the game's setting went from brothels to urban parlors; while other holdovers from "old China" like footbinding and opium smoking were clearly "bad," for many players, mahjong seemed to be an innocuous pastime. As the game became increasingly associated with elite, thoroughly modern segments of society, the consequences of a nation engaged in mahjong playing seemed ever more dire.

At the same time, some writers recognized that mahjong was merely a symptom, not the cause, of problems faced by urban residents, particularly women. In a compelling Women's Voice article from 1947, the reader is drawn to a cartoon labeled "Still Comrades" ("Naiyi" 1947, 18). Four women hunker down over a mahjong game, complaining about their husbands. "My husband's a refrigerator," one says. "My husband is as cold as the snow of the Himalayas," grouses another, while the next states that her husband is like a block of marble. "My husband is hot as a volcano," declares the last, "but he only uses his heat on the body of his secretary." Mahjong is simply a facilitator for the conversation happening at the table, and it is this social quality that the article takes up in discussing mahjong clubs. Although the article takes a stance 
against mahjong associations, considered excessively popular among women, the author notes that love of the game springs from social causes. Outlining a number of sad stories, it is hard not to sympathize with women who found an escape from daily life with their mahjong friends. Some stories could come from any period - the cooling of marital affection, or the depression created by a cheating spouse - but a few seem unique to the modern age. One woman, described as bright, educated, and outgoing, was stuck at home with a husband who refused to let her work outside the home. Her neighbors noticed she was deeply unhappy and pulled her into their mahjong circle, giving her something to look forward to. Another woman convinced her husband to join in games, theorizing that if they were playing mahjong together, he could not be out carousing.

While driving home all the negative consequences of mahjong in rather dramatic termschiefly, neglecting children - the author also notes that the root causes of such unhappiness need to be addressed. Mahjong is here merely a symptom of a society in trouble. Educated women were being driven into the arms of mahjong "comrades" as an alternative to suicide: what was it about Chinese society that was allowing this to happen? The author does not say, but mahjongwhich was well-traversed ground for critics searching for a scapegoat - and the women who played it were convenient figureheads for bigger problems facing wartime China in the tumultuous 1940s. The implication that women would be better served by joining women's associations__ presumably ones addressing social or political issues_instead of "wasting time" playing mahjong is one connection to earlier harsh critiques of mahjong and madiao. However, the pleasure of mahjong for the women discussed is not the game itself, but the community and opportunity for socializing. Would — or could—purposeful women's associations serve the same role? Or was the space created by mahjong societies attractive precisely because it was free from "productive" activity, and offered the chance to escape from daily life?

\section{Nationalism and Mahjong}

The concern over what people did with their free time, and the corresponding idea that leisure time ought to be taken up by meaningful activities, is a unique feature of Republican-era discourse when compared to earlier periods. While Qing critiques give the impression that authors felt there were, perhaps, better activities for scholar-officials to be engaged in (such as weiqi), there is little trace of the "time-wasting" discourse that dominated writings on mahjong 
from the late 1910s onward. Qing moralists may have looked upon mahjong as something beneath the educated gentry, but Republican nationalists perceived it as something that wasted the vast manpower of China. Concerns over nation building collided with private life in ways that echoed the discourses surrounding etiquette, education, and child rearing. But attempts to reform attitudes toward mahjong were, by and large, confined to the pages of journals and newspapers: actions to get rid of the game were few and far between.

One of the sharpest critiques came in 1914, in the form of a faux classical history. Playing on both a standard literary style and mahjong's alternate name of maque (sparrow), the article by the pseudonymous "Yabi" appeared in the appropriately titled Pastime Magazine. The title_- "Annals of the Sparrow King" - plays on classical histories with its use of the term benji (Chinese dynastic histories), and the contents read as an imitation of official histories. "In the waning years of the Qing," the author writes in a high literary idiom, "control [of the empire] was lost. All under heaven was agitated; a group of heroes rose up, and this was the reason for the fall of the dynasty" ("Yabi" 1914, 7). The dubious heroes of the story include the kings of pornography, railroads, "wild chickens" (prostitutes), and opium, who each raise an army in various corners of China. Yet until mahjong - the Sparrow King - flies onto the scene, no one can unite the country: only mahjong manages to pull together the North, the South, the East, and the West (a reference to the four directional tiles of the game) in combat. In language borrowed from antiquity, "Yabi" skewers the game of mahjong, China's long-standing social problems, and the fall of the Qing in one fell swoop. Yet even in the midst of exceedingly literary satire, the author underscores the great fear regarding mahjong: its insidious ability to attract players from all walks of life, all ages, and both genders. The message was one that would be repeated over and over: while big problems, like chaotic political systems and Western imperialism, may have captured the lion's share of attention, seemingly inconsequential matters were perhaps even more serious issues.

In many respects, the new Republican discourse shared striking similarities with discussions of madiao and mahjong from the Qing, and even the old foil of weiqi emerged once again as an appropriate pastime for citizens of a new China. The same false dichotomies remained, but with an added emphasis on the health of the nation and regulation of leisure time. And yet mahjong, in contrast to casinos, dog and horse racing, and other fast forms of gambling, was not the focus of sustained governmental efforts to regulate gambling (Wakeman 1994, 24- 
25), perhaps because of its more private nature. Because mahjong required only a table and a tile set, one was able to enjoy a single hand or eight without leaving the house. Mahjong's innocuous nature - to the point that the game had "ceased to be seen as gambling at all," at least in some areas - had become part of a normal, bourgeois domestic scene (Ho 2005, 209).

Still, reformers and intellectuals in Republican China were consumed with the business of shaping a new nation, from the political system to the domestic sphere. Efforts to control leisure time and spaces were part of the effort to create "a modern municipal culture" that was one piece of the "national effort to make "citizens'... out of 'people"" (Wakeman 1994, 20). Creating citizens required more than just shaping urban residents who did not spit on the floors of movie theaters or spend their savings at the racetrack. The problem Republican reformers bumped up against with mahjong was that the game seemed to symbolize some deeper moral deficiency that getting rid of the game could not fix.

In Hu Shi's essay on mahjong, which included his calculation that four million manhours a day were lost to the game, he considered it's spread to Japan and the West. "Who would have imagined," he marveled, that "those hundred and thirty-six mahjong soldiers [tiles]" ([1927] 1998, 46) would be the first piece of Asian culture to conquer the West? And yet the craze quickly cooled. He asked an American friend why the mahjong fad faded so quickly and was told that "women really like mahjong; however, men opposed it, and at long last, the men won out" ([1927] 1998, 46). Hu Shi does not dwell on this gendered perspective too long, since the problem goes far deeper than Chinese women's fondness for the game. "Hardworking," "ambitious" Western people (which probably ought to be read as "men") would neither become "disciples of" nor "submit to mahjong" ([1927] 1998, 46). Mahjong was a uniquely Chinese problem: the "patented product" of an "intellectual civilization" (Hu [1927] 1998, 46) that did not value time and preferred loafing about. Unlike the Qing critics, Hu Shi is not proposing a more appropriate use of time via weiqi. Contemplating the universe on a weiqi board would likely be nearly as wasteful as playing mahjong - the emphasis on the individual, either in contemplation or private pleasure, took away from the emphasis on the nation. This idealistic vision, even if partially tongue in cheek, ignored the reality that people, no matter how industrious in spirit, could not work all the time.

But not everyone parroted this discourse that "patented products" of China's intellectual past were a waste of time. Weiqi still enjoyed some status as an appropriate pastime, and one 
1939 article entitled "Chatting about weiqi" outlined why weiq $i$ was the "most opportune pastime for today's youth" (Han 1939, 60). It was a "national product" (but with a much more positive cast than mahjong received in Hu Shi's assessment), it was inexpensive, and it could be played anywhere at anytime. Furthermore, even though there were only two players, "many more" could sit by and watch. The article goes on to discuss why weiqi-despite the opinion of some people that play had no place in the war of resistance - was in fact an appropriate pastime, since one could hardly expect people to do nothing but read books and study. Once again, the supposed applicability of weiqi's broader lessons garnered it a position as an "appropriate" pastime, particularly as such lessons could be located in the classics and classical literature (Han 1939, 62). Perhaps it was this reliance on classical precedents to justify some "wasteful" games and not others that led the Shanghai publication Movietone to publish a little satire called the "Mahjong Analects" ("Majiang" 1940). Parodying the Analects of Confucius, the first line reads: "The Master said: 'Playing mahjong for a long time, is this not a joyous thing?"”

Mahjong players countered official perceptions of their pastime as a nefarious time waster. As described by historian Virgil Ho, devotees in Guangzhou protested a 1936 ban on gambling that included a prohibition on mahjong. Mahjong was described, just as it was in the Women's Voice article a decade later, as a highly social game that allowed for the deepening of social bonds. And, in an eminently practical manner, the petitioners pointed out that mahjong provided revenues for local governments, as well as for restaurants that allowed the game to be played on their premises (Ho 2005, 211).

Presentations of mahjong as a pleasant diversion competed with essays decrying the dangerous nature of the game. "I didn't used to like mahjong," the pseudonymous author "Bingsheng" wrote in the early 1940s. "I couldn't stand watching classmates play" $(1941,385)$. But, from 1937 onward - the so-called "Orphan Island" period between 1937 and 1941, when Shanghai maintained some autonomy in the midst of the Japanese invasion-things were busier than ever, and the pleasures of the city were more difficult to come by. "Of course people can't only work and have no fun... It was at this time I started to play mahjong" (Bingsheng 1941, 385). The simple observation that people need free time is one that rarely comes up in harsh critiques centered on "wasting time." In some ways, this piece is a mediation of many earlier critiques. On the one hand, the author recognizes the addicting power of the game and believes some sort of reform is necessary. Yet his acknowledgment that mahjong is not going to 
disappear, and that people are never going to devote the entirety of their lives to "productive" matters, is rare among Republican criticism. His simple fix for mahjong is to remove the gambling aspect from the game, noting that the Japanese picked up mahjong as entertainment, and not as a form of gambling. Bingsheng notes, too, that mahjong is simply "too common" to be changed on its own; for reforms to stick, reforms of mahjong would have to be carried out at the same time as larger social reforms $(1941,389)$.

But mahjong resisted reforms. The general public never saw it as a dangerous scourge, but rather as a pleasurable, innocuous diversion. The government could go only so far in regulating public life, and mahjong was usually a private activity, played within the confines of one's home. Mahjong remained firmly entrenched in parlors and living rooms, secure in an area that the state - particularly in a period of upheaval-had difficulty controlling. The problem must have been maddening for enthusiastic reformers, particularly when the game could be used as cover for subversive activities. In 1949, the leftist intellectual Wu Han managed to host gatherings to discuss politics and current events at his home, even though he was "under the constant gaze of [Nationalist] security forces" (Mazur 1993, 46). How? By hosting mahjong and bridge parties. The clattering of mahjong tiles could, and did, cover up conversations on many topics.

\section{The Game People Played}

Why did mahjong so arouse Qing moralists and Republican reformers? Few critics enumerate their displeasure in a straightforward manner. For critics in the Qing dynasty, the game's link with madiao — the game that "lost the Ming" — and the game's birth during a period of foreign incursion and domestic turmoil seem to be likely reasons for a deep-seated, if not entirely rational, dislike of the game. Lacking a Confucian pedigree and emphasizing chance over cultivated skill, mahjong had neither the blessing of sages nor the promise of selfimprovement. It was social, noisy, seemingly lacking in virtues. The cosmos, at least as many scholars wished to envision it, was emphatically not a mahjong table. If weiqi allowed players to retain control over their fate in a match, mahjong and madiao taunted them with the truth that nothing could make up for a bad hand. Mahjong's rise, though mostly obscured in the record, came during a period marked by China's humiliating defeat in the Opium Wars and the devastating Taiping Rebellion. The game, from its ties to madiao to its emergence in this period, 
carried more than a small whiff of failure. Perhaps moralists' anxiety was underpinned by an unconscious recognition that madiao and mahjong reflected the world of the late Qing, where no amount of cultivation and refinement could make up for imperialism and decline.

By the waning years of the Qing, the game's association with the seedier side of Chinese society obscured mahjong's place in the social life of the elite. The Republican period inherited the expressed disapproval of the game, and in the early years, moralists were primarily concerned with backward pleasures like courtesans and opium. However, it was the realization that mahjong could not be ascribed solely to one part of society that proved the most enduring and frightening aspect of the game for Republican critics. While opium smoking and footbinding receded into China's past, mahjong remained firmly in its present. In 1934, an article declared that mahjong was "an authentic example of "Chinese learning as the substance"” (Hai 1934, 4-5), a sarcastic reference to failed attempts at military and political modernization in the Qing. It was complicated, not standardized, and emphasized combat. The fact that people could while away hours upon hours on a silly game of so little substance was baffling — and concerning.

In the People's Republic of China, the game was generally discouraged after 1949 and finally formally banned in the 1960s, along with other kinds of gambling (Wang 1995, 160-161). In Taiwan, the Nationalists likewise banned all forms of gambling, and mahjong with it. Paul Festa notes the peculiar position of mahjong in contemporary Taiwanese society, which could be read as a somewhat natural outcome for a game that has occupied a conflicted status in Chinese society from its very origins. Hu Shi's sarcastic note that mahjong was the "national game" of China has been taken on by the Republic of China quite seriously: mahjong is banned, and yet it is included on the "exclusive list of approved activities for "Art and Folkway Associations"” ([1927] 1998, 97). Festa writes of "mahjong dragnets" that Republican critics could only have dreamed of: "ongoing and dramatic raids on mahjong gambling rings with police kicking down doors and brandishing rifles [that] are captured live by the media - in what [informants] insist are staged performances - and featured on the evening news" ([1927] 1998, 98). Would earlier critics be disturbed to learn that, even with formal bans in place, mahjong remains a "universally popular illegal activity" (Festa 2007, 99)? Mahjong still provides an example for later ludic descendants: games that exist in an uneasy space between the sanctioned and the proscribed.

\section{Maggie Greene is assistant professor of History at Montana State University.}


Notes

1 Any English translation misses Lu Xun's emphasis on the foreignness of mahjong to this peasant: the characters he uses are also pronounced majiang, which means "sesame paste" (Lu 1994, 99).

2 Gail Hershatter describes the "white-board face off" (baiban duisha) situation, in which two men compete for the attention of a single courtesan. Mahjong sets "included four blank tiles, nicknamed 'small white faces' (xiao bailian)" (135), which the historian explains was also a term for handsome young men who patronized brothels. In order to make a set of blank tiles during a mahjong game, a team needed three of the four tiles; situations where each team held two blank tiles - and the ensuing stalemate-were termed "white-board face offs" (1997, 135-136).

3 This early attempt at creating "edutainment" in many ways foreshadows contemporary attempts by governments to regulate digital game spaces and turn them into areas for productive leisure.

\section{References}

Ackermann, Robert John. 1990. Nietzsche: A Frenzied Look. Amherst: University of Massachusetts Press.

Aoki Masaru. 1964. Pekin fuzoku zufu [Illustrations of Beijing customs]. Tokyo: Heinbonsha. "Bingsheng." 1941. "Tan majiang" [Chatting about mahjong]. Wenxin 385-389.

Cao Xueqin. 1977. The Story of the Stone. Vol. 2. Translated by David Hawkes. New York: Penguin.

Chen Xiyuan. 2009. "Cong madiao dao majiang — xiao wanyi yu da chuantong jiaozhi de yi duan lishi yinyuan" [Madiao and mahjong in popular culture and elite discourse]. Zhongyang yanjiuyuan lishi yuyan yanjiusuo jikan 80 (1): 137-196.

Chen Zuyan. 1997. "The Art of Black and White: Wei-ch' $i$ in Chinese Poetry." Journal of the American Oriental Society 117 (4): 643-653.

- 2001. "Shao Yong's (1011-77) 'Great chant on observing 'weiqi': An Archetype of Neo-Confucian Poetry." Journal of the American Oriental Society 126 (2): 199-221.

Dixon, Dan. 2009. "Nietzsche contra Caillois: Beyond Play and Games." Paper presented at the annual Philosophy and Computer Games Conference, Oslo, Norway, August 13-15.

Du Yaquan. 1933. Boshi [History of gambling]. Shanghai: Kaiming shudian.

Festa, Paul E. 2007. "Mahjong Agnostics and the Political Public in Taiwan: Fate, Mimesis, and the Martial Imaginary." Anthropological Quarterly 80 (10): 93-125.

Gibson, Walter B. (1974) 2013. Hoyle's Encyclopedia of Card Games: Rules of All the Basic Games and Popular Variations. New York: Broadway Books.

Hai Ge. 1934. "Tan majiang" [Chatting about mahjong]. Renjian shi 12: 4-5.

Han Banqing. 2005. The Sing-Song Girls of Shanghai. Translated by Eileen Chang and edited by Eva Hung. New York: Columbia University Press.

Han Baomin. 1939. "Tan weiqi” [Chatting about weiqi]. Zhanshi zhongxuesheng 1939 (12): 6062. 
Hershatter, Gail. 1997. Dangerous Pleasures: Prostitution and Modernity in Twentieth-Century Shanghai. Berkeley: University of California Press.

Ho, Virgil K. Y. 2005. Understanding Canton: Rethinking Popular Culture in the Republican Period. Oxford: Oxford University Press.

Hu Shi. (1927) 1998. "Majiang” [Mahjong]. In Hu Shi quanji, di 3 juan [Collected works of $\mathrm{Hu}$ Shi, volume 3], edited by Ji Xianlin, 45-48. Hefei: Anhui jiaoyu chubanshe.

Huizinga, Johan. 1971. Homo Ludens: A Study of the Play Element in Culture. Boston, MA: Beacon Press.

Laogong zhi aiqing [Laborer's love]. 1922. Directed by Zhang Shichuan. China: Mingxing. Li Chunping. 2009. "Xihuan da majiang de shehui mingliu" [Noted public figures who enjoyed playing mahjong]. Banyue xuandu 21: 26-27.

Lien, Y. Edmund. 2006. "Wei Yao's disquisition on boyi." Journal of the American Oriental Society 126 (4): 567-578.

Lo, Amy. 2001. The Book of Mahjong: An Illustrated Guide. North Clarendon, VT: Tuttle Publishing.

Lo, Andrew, and Tzi-cheng Wang. 2004. "Spider Threads Roaming the Empyrean: The Game of Weiqi." In Asian Games: The Art of Contest, edited by Colin Mackenzie and Irving Finkel, 186-201. New York: Asia Society.

Lu, Xun. 1990. “Ah Q-The Real Story.” In Diary of a Madman and Other Stories, translated by William A. Lyell, 101-172. Honolulu: University of Hawai'i Press. . 1994. "A Q zhengzhuan" [The true story of Ah Q]. In Lu Xun xiaoshuo ji [Collected short stories of Lu Xun], edited by Yang Ze, 75-120. Taipei: Gongfan shudian.

"Majiang lunyü" [Mahjong analects]. 1940. Diansheng 7.

"Majiang pai gaige yi'an" [A proposal to reform mahjong tiles]. 1904. Jingzhong ribao, March 14.

Mazur, Mary. 1993. "Intellectual Activism in China during the 1940s: Wu Han in the United Front and the Democratic League." China Quarterly 133: 27-55.

McCormack, Gavin. 1977. Chang Tso-lin in Northeast China, 1911-1928: China, Japan, and the Manchurian Idea. Stanford, CA: Stanford University Press.

Mei Jun. 1940. "Majiang zai Zhongguo" [Mahjong in China]. Zhongguo funü 3: 17.

"Minzhengbu jiang shixing jindu" [Ministry of civil affairs will implement a ban on gambling]. 1909. Shenbao, August 9.

"Naiyi." 1947. "Taitaimen weishenme xihuan cuo majiang?" [Why do women like playing mahjong?]. Nüsheng 7: 18.

Papineau, Élisabeth. 2000. Le jeu dans la Chine contemporaine: Mah-jong, jeu de go et autres loisirs [Play in contemporary China: Mahjong, the game of go, and other recreation]. Paris: L'Harmattan.

Pickowicz, Paul G. 1991. "The Theme of Spiritual Pollution in Chinese Films of the 1930s." Modern China 17 (1): 38-75.

Shao, Qin. 1998. "Tempest over Teapots: The Vilification of Teahouse Culture in Early Republican China." Journal of Asian Studies 57 (4): 1009-1041.

Wakeman, Frederic, Jr. 1994. "Licensing Leisure: The Chinese Nationalists' Attempt to Regulate Shanghai, 1927-49." Journal of Asian Studies 54 (1): 19-42.

Wang, Shaoguang. 1995. "The Politics of Private Time: Changing Leisure Patterns in Urban China." In Urban Spaces in Contemporary China: The Potential for Autonomy and 
Community, edited by Deborah S. Davis, Richard Kraus, Barry Naughton, and Elizabeth J. Perry, 149-172. Cambridge: Cambridge University Press.

Xiao tianshi [Little angel]. 1935. Directed by Wu Yonggong. China: Lianhua.

Xu Ke. (1917) 1984-1986. Qingbai leichao [Classified collection of Qing notes]. Beijing: Zhonghua shuju.

"Yabi." 1914. "Maque dawang benji" [Annals of the mahjong king]. Youxi zazhi 7: 7-8. 